\title{
DISCUSSÃO SOBRE A ATUAL CARTOGRAFIA GEOTÉCNICA DO MUNICÍPIO DE SÃO PAULO E SUAS POSSÍVEIS APLICAÇÕES
}

\author{
ALEX UBIRATAN GOOSSENS PELOGGIA*
}

\begin{abstract}
DISCUSSION ABOUT THE ENGINEERING GEOLOGICAL MAPPING OF SÃO PAULO CITY, AND ITS APPLICATIONS From the 80's, the territory of São Paulo City has been subject of Engineering Geological Mapping in progressively more detailed scales of representation $(1: 50.000 ; 1: 25.000 ; 1: 10.000)$. Through the revision in its methods, objectives, pressuppositions and products, of the maps in 1:50.000 and 1:25.000, it was searched for a discussion about the recent use of this cartography in 1:10.000. It showed that this work of detailment did not represent a significant qualitative improvement and, moreover, it stopped considering the importance of more recent processes and deposits, resulting of human - or technogenic - action, that cause significant urban geological problems.
\end{abstract}

Keywords: Engineering Geological Maps, São Paulo City, methodology

RESUMO A partir dos anos 80 o território do Município de São Paulo vem sendo objeto de Cartografia Geotécnica, em escalas de representação progressivamente mais detalhadas $(1: 50.000 ; 1 \cdot 25.000 ; 1: 10.000)$. A partir da revisão das cartas geotécnicas em $1: 50.000$ e $1: 25.000$, em seus métodos, objetivos, pressupostos e produtos, buscou-se a discussão do trabalho de detalhamento em 1:10.000 dessa cartografia, recentemente produzido, demonstrando que tal trabalho não representou um aprimoramento qualitativo significativo e, além disso, deixou de considerar a importância dos processos e depósitos mais recentes e significativos na geração de problemas geológicos urbanos, aqueles resultantes da ação humana ou tecnogênicos.

Palavras-chave: Carta Geotécnica, Município de São Paulo, metodologia

INTRODUÇ̃̃o O Município de São Paulo tem sido objeto de cartografação geotécnica, em diversas escalas, a partir de meados dos anos 80 , seja englobando-o enquanto território integrante da Região Metropolitana de São Paulo, seja abrangendo-o especificamente, no todo ou parcialmente. Faz-se necessária portanto uma discussão introdutória para comentarmos os produtos de tais trabalhos, oriundos da iniciativa de instituições governamentais da administração direta ou indireta, antes de passarmos à análise global. Comentaremos, portanto, uma a uma, as principais "Cartas Geotécnicas" efetuadas em bases territoriais-políticas referentes à capital paulista, enfocando particularmente seus métodos, objetivos e pressupostos.

\section{A CARTA GEOTÉCNICA DA GRANDE SÃO PAULO} EM ESCALA 1:50.000 (1985) Conforme Prandini et al. (1995), tal Carta, desenvolvida pelo Instituto de Pesquisas Tecnológicas do Estado de São Paulo -IPTe Emplasa, iniciouse a partir do exame e concepção de alternativas para projetos de parcelamento do solo. Nas palavras de Prandini et al. (1992), a Carta Geotécnica da Grande São Paulo apresenta os terrenos metropolitanos agrupados em oito unidades homogêneas quanto aos problemas existentes e potenciais, sendo os mais freqüentes a erosão intensa dos materiais expostos por movimentos de terra, as enchentes das glebas mais baixas e os escorregamentos induzidos em aterros e cortes. Segundo os autores citados, essas oito "unidades homogêneas" se subordinam aos "sistemas de relevo", os quais foram definidos por "conjuntos de formas basicamente comparáveis quanto às suas amplitudes e declividades". O conjunto de sistemas de relevo característicos do território metropolitano incluiria categorias bem marcadas, englobando várzeas, colinas, morrotes, morros e outros relevos montanhosos e escarpas serranas. Conforme os autores, as unidades homogêneas traduziriam, secundariamente, também a natureza dos materiais: diversas rochas cristalinas, sedimentos da Formação São
Paulo (sensu lato) e seus solos derivados, além de depósitos inconsolidados das várzeas.

Esses mesmos autores supracitados, no entanto, ressaltam a deficiência de sua utilização: "A própria Carta Geotécnica da Grande São Paulo, se bem que acessivel na biblioteca desses órgãos [IPT e Emplasa], nunca chegou a ser publicada em sua totalidade como trabalho técnico de divulgação ou, mesmo, formalmente, como parte integrante de ato de orientação elou normatização" (Prandini et al. 1992).

\section{A "CARTA DE APTIDÃO FíSICA AO ASSEN- TAMENTO URBANO" EM 1:50.000 (1990) Tal} Carta, surgida ao público em 1990, representa a revisão e atualização da "Carta Geotécnica da Grande São Paulo", e caracteriza-se essencialmente pela definição de unidades homogêneas definidas a partir de "padrões de relevo" (baseados na declividade, amplitude e linhas de drenagem) e do substrato geológico (a partir do mapa geológico da Grande São Paulo de J.M.V. Coutinho, 1980, publicado pela Emplasa), e "agrupando-se os tipos de rochas que apresentassem caracteristicas semelhantes " (GESP, 1990). Isto se baseia no pressuposto de que o padrão de relevo seria um indicador das potencialidades e limitações para a expansão urbana, e o tipo de rocha possibilita a previsão das características dos solos encontrados nas unidades (GESP, 1990).

As trinta e quatro "unidades homogêneas" assim consideradas, constituiriam "áreas que apresentam comportamentos semelhantes, em termos de dinâmica do meio fisico, frente às diversas solicitações impostas pelas práticas correntes de urbanização". Ressalte-se que são objetivos explícitos da Carta apresentar "orientações para a expansão urbana e critérios para a elaboração de projetos de parcelamento do solo " (GESP, 1990), mas através principalmente da legislação de uso do solo, a qual pretende subsidiar, ao apontar os tipos de problemas geotécnicos característicos das diversas unidades mapeadas e assinalar critérios para uma "ocupação

Rua Amaral Gurgel 468 - Apto. 103, 01221-000 - São Paulo - SP

Não analisaremos aqui a "Carta Geotécnica dos terrenos adjacentes ao Tietê", de Prandini et al. (1978), ou outras de mesma natureza que por suas especificidades não se enquadram no conjunto das cartas geotécnicas efetuadas em função de bases territoriais políticas.

Os sistemas de relevo, na concepção expressa por Ponçano et al. (1979) e Ponçano et al. (1981), e utilizada no Mapa Geomorfológico do Estado de São Paulo, do IPT, referem-se a "áreas cujos atributos fisicos sejam distintos das áreas adjacentes ", em função de "padrões recorrentes de topografia, solos e vegetação,

(...) correlacionados com geologia, geomorfologia e clima". 
mais racional" (GESP, 1990), além de fornecer "subsídios para a preparação de planos diretores".

É reconhecido, no entanto, que "a escala 1:50.000 apresenta recomendações de caráter mais geral, ou seja, contém dados a nivel regional, sendo, portanto, um instrumento de orientação ao crescimento urbano. Pela própria escala, não é possível uma visualização a nível de quadra ou lote, o que não permite estabelecer exigências específicas para porções de um mesmo loteamento" (GESP, 1990)

A CARTA GEOTÉCNICA DO MUNICÍPIO DE SÃo PAULO EM 1:25.000 (1985) Na descrição de Prandini et al. (1992), a Carta Geotécnica do Município de São Paulo traduz o território paulistano em três unidades homogêneas, refletindo hierarquicamente (isto é, em termos de classificação e ordenamento) a energia de relevo de elementos geomorfológicos e as características dos solos e rochas. A intenção era, assim, procurar representar a "máxima síntese possível das informações, destacando o necessário e suficiente para embasar diretrizes distintas de uso do solo, voltadas a reduzir substancialmente os problemas originados do uso descriterioso do solo na Capital". ^

Conforme descrevem Ávila et al. (1987), tratava-se de definir "áreas cuja resposta ao uso e ocupação possam ser tratadas deforma uniforme", com a finalidade de "orientar os processos mais econômicos de desenvolvimento de ocupação urbana da cidade". Para tanto, foram definidos: três tipos de áreas conforme o "estágio de urbanização"; três tipos de "setores de relevo" (várzeas e fundos de vale; setores côncavos de encosta ou com declividades altas; setores convexos do relevo, topos de morros e encostas suavizadas); e três tipos de maciços "terrosos e rochosos", a saber: 1) sedimentos aluvionares e solos hidromórficos; 2) sedimentos da Formação São Paulo; 3) granitos; gnaisses graníticos; xistos micáceos; xistos quartzosos; "maciços mistos"; filitos; anfibolitos.

Informam Prandini et al. (1992) que "além das (...) inclusões nos Planos Diretores Municipais - PDMs - de 1985 e 1991, a Carta Geotécnica do Município vem subsidiando diretamente intervenções preventivas nas "áreas de risco" ocupadas por favelas e, também, no aperfeiçoamento de diplomas legais como o Código de Uso do Solo e o Código de Obras. Esta Carta, hoje, serve de base para os trabalhos de geração de uma carta geotécnica detalhada do Município, na escala 1:10.000, que vem sendo produzida por técnicos da Prefeitura do Município de São Paulo". Esta descrição, corroborada em versão oficial pela PMSP (1992a), apresenta no entanto sérios problemas.

No entanto, o atual Código de Obras e Edificações do Município de São Paulo (Lei n 11.228 de 25 de junho de 1992, juntamente com o Decreto Regulamentador $\mathrm{n}^{\circ} 32.329$ de 24 de setembro de 1992) não trata de quaisquer assuntos especificamente geotécnicos. Em seu capítulo 10, seção 14, que trata dos "movimentos de terra", limita-se a considerações genéricas e extremamente curtas. O Decreto Regulamentador, por sua vez, limita-se a definir que: "O movimento de terra em terreno lindeiro a cursos d'água ou linhas de drenagem, em área de várzea alagadiça, de solo mole ou sujeita a inundações, em área declarada de proteção ambiental ou sujeita à erosão, já delimitada pela PMSP, terá sua análise e licenciamento regulamentados pelo Executivo". Regulamentação esta que desconhecemos até hoje.

Quanto aos Planos Diretores, consideraremos os Projetos de Lei de 1985 e 1991. Realmente, segundo uma análise efetuada para o projeto do Plano Diretor do Município de São Paulo de 1985, "o sítio urbano de São Paulo possui algumas características que conferem especificidade à problemática de sua urbanização. Apresenta compartimentos bastante diversificados resultante de condições geomorfológicas, principalmente no que se refere ao relevo è à drenagem: planícies fluviais, um sistema de colinas e de vales de médias declividades e áreas periféricas de altas declividades, a Serra da Cantareira ao Norte, a Serra do Mar ao Sul e formações mais descontínuas a Leste e Oeste" (PMSP, 1985).

No entanto, os dados da "Carta" são citados unicamente na elaboração de um mapa de "erosão de solos", em escala pequena, o qual identifica sete "compartimentos" classificados em "não-vulneráveis" (essencialmente os terrenos da Bacia de São Paulo), e "vulneráveis", e aos quais se associam "diretrizes para ocupação urbana", colocadas em termos de "graus de complexidade".

Apesar da evidente imprecisão dos conceitos e excessiva generalização, tal diagnóstico pretendia conduzir, ao apreender tais especificidades, a uma interação racional entre a ocupação urbana e as características do ambiente: "o Plano deverá dirigir a produção do espaço urbano de forma a ocupar adequadamente os diversos compartimentos geomorfológicos, otimizando o seu potencial de relevo, solo, drenagem e vegetação, em todas as escalas. Na macroescala, deverá criar um mosaico de áreas urbanizadas e grandes espaços abertos, preservando e protegendo os elementos paisagísticos relevantes do sítio urbano, desde a macrodrenagem e relevo até a vegetação remanescente. Na microescala, deverá garantir padrões de qualidade ambiental pela regulamentação do uso e ocupação do solo e das edificações, tendo em vista o estabelecimento de relações quantitativas e qualitativas das edificações com os espaços abertos que as envolvem" (PMSP, 1985).

O Projeto de Lei do Plano Diretor do Município de São Paulo de $1991^{3}$, publicado no Diário Oficial do Município em fevereiro daquele ano, tratava, em seus artigos 34 e 35, das então denominadas "áreas de interesse ambiental", e incluía entre elas os terrenos situados em várzeas, "meia encosta" ou ainda com "alta declividade e sujeitos à erosão". Tais áreas são apresentadas, incluindo-se também "perímetros com concentração de altas declividades", em um mapa de escala pequena, anexo ao Projeto de Lei, no qual aparecem como manchas grosseiramente delineadas, e incluem indiscriminadamente todas as "várzeas" dos rios principais e córregos mais significativos, independentemente de seu grau de ocupação e transformação. Para essas áreas, assim precariamente representadas, são estabelecidas taxas de ocupação, taxas de permeabilidade e índices de áreas verdes, assim como "faixas non aedificandi" variáveis, e chegando a englobar toda a largura das várzeas na zona rural.

O Projeto de Lei estabelecia que: "Nas áreas com alta declividade sujeitas à erosão e nos perímetros com grande incidência dessas áreas serão exigidos: a) alvará de execução para movimento de terra em qualquer terreno, condicionado a projeto e responsabilidade técnica de profissional contratado pelo empreendedor; b) projeto especial de parcelamento do solo visando minimizar movimentos de terra e controlar o processo de implantação do empreendimento".

No entanto, se a Carta Geotécnica foi utilizada como base para a definição das áreas acima consideradas, não era feita no Projeto de Lei nenhuma relação entre a definição dessas áreas e a Carta, nem tampouco qualquer referência à mesma. Por fim, quanto à utilização de informações nas intervenções preventivas em áreas de risco ocupadas por favelas, a partir de 1989, citada também por Prandini et al. (1995), alguns pontos devem ser ressaltados: em primeiro lugar, é sabido que a seleção das favelas a serem analisadas em tal levantamento foi efetuada a partir da memória de atendimentos da Prefeitura do Município (PMSP, 1992b; Peloggia et al., 1992) e, se a Carta foi levada em conta, não teve papel preponderante; em segundo lugar, a própria metodologia de análises de riscos desenvolvida pelo IPT (Cerri \& Carvalho, 1990) não guarda nenhuma relação direta com quaisquer das informações da Carta; e, em terceiro lugar, em nenhum dos 240 relatórios de 
análise de riscos produzidos pela Prefeitura de São Paulo observa-se qualquer utilização das informações da Carta na definição e hierarquização das "áreas de risco".

\section{A CARTA GEOTÉCNICA DO MUNICÍPIO DE SÃO} PAULO EM 1:10.000 O detalhamento da Carta Geotécnica do Município de São Paulo, na escala 1: 10.000, efetuado por uma equipe da Prefeitura de São Paulo, com assessoria do IPT, colocava como objetivos iniciais os seguintes pontos (PMSP, 1992a), que passamos a comentar um a um:

- "a formulação de instrumentos normativos específicos para operações de urbanização, baseados em indicadores apropriados" (grifo meu). Trata-se de um objetivo incompatível com a escala, caso se visem realmente as especificidades $_{t}$ isto é , operações determinadas em locais definidos. Isto é demonstrado por exemplo pela necessidade de adoção de escalas de trabalho muito mais detalhadas, como por exemplo em projetos de urbanização de favelas, conforme tem sido descrito na literatura (Peloggia, 1992; Barros \& Peloggia, 1993; Pupo \& Lopes, 1993; Gonçalves \& Brollo, 1993, entre outros).

- "a consolidação de procedimentos orientativos para operações de licenciamento de obras, consubstanciados em características distintivas de interesse dos variados terrenos do território paulistano". No entanto, não é possível generalizar de tal modo, dadas as peculiaridades locais assim como a variabilidade das obras, de forma a não se chegar meramente a recomendações óbvias, por um lado, além de correr-se o risco de restrições (ou permissões) descabidas, por outro. Nesse sentido, as palavras de Ab' Saber (1977), apesar de não diretamente relacionadas ao tema que tratamos aqui, expressam muito bem a generalidade dos problemas de qualquer contexto de manejo do espaço: "cada área e cada gleba tem os seus próprios problemas de preservação e manejo racional do espaço. Razão porque cada caso é um caso, do ponto de vista da (...) proteção dos tecidos ecológicos".

Seguindo com os objetivos em análise:

-"orientação geral para medidas corretivas/preventivas em áreas de risco, incluidas sua identificação prévia, critérios para hierarquização das ações e diretrizes de intervenção". Novamente, objetivo incompatível com a escala adotada; de fato, e apesar de possíveis opiniões em contrário, a prática tem mostrado que na identificação de áreas de risco, no Município de São Paulo, não tem sido significativa a contribuição da Carta Geotécnica, conforme mostramos na discussão anterior sobre a Carta em 1:25.000. No máximo, e esse poderia ser realmente um aspecto bastante útil, prestar-se-ia a Carta ao cadastramento da ocorrência de áreas com situações de risco.

-"subsídios para o entendimento e enfrentamento de problemas geológico-geotécnicos que se manifestam no espaço urbano através de ocorrências como enchentes, erosão, recalques etc...". Uma colocação tão genérica que se aplica a qualquer escala. Apesar destes poderem ser considerados, por assim dizer, "princípios básicos" da Cartografia Geotécnica, tratam-se de questões que, em nossa opinião, merecem ser melhor discutidas em termos metodológicos, o que não poderemos fazer aqui.

- "identificação de áreas mais adequadas para a disposição de entulho e lixo em aterros sanitários". Tratava-se, aqui, de um objetivo factível, desde que em caráter preliminar, não dispensando no entanto o estudo detalhado em cada local selecionado. Seja como for, a proposta não foi levada adiante.

-"orientação para o processo de expansão urbana, através da identificação de potencialidades e limitações dos terrenos". Conforme o relatório final do Grupo de Trabalho constituído, no âmbito da Prefeitura de São Paulo, para a execução da Carta (PMSP, 1994), "a Carta Geotécnica é uma fonte de informações onde dados como solos, rochas, morfologia do relevo, drenagem e ocorrências especiais como escorregamentos, surgências d'água etc., são representados cartograficamente deforma que ao serem conjugados com a forma de ocupação, possibilitem a interpretação do meio físico e avaliação das potencialidades e limitações ao uso e ocupação do solo. Fornecendo indicadores mais precisos para determinar potencialidades do meio fisico para uso e ocupação urbanos, a Carta deverá subsidiar ações normativas, corretivas e fiscalizatórias do poder público. /.../Traduzindo informações para uma linguagem acessível, pretende uma divulgação que extrapole instâncias exclusivamente técnicas e a sua incorporação como instrumento de trabalho nas rotinas da atuação dos setores administrativos e executivos que lidam com a fiscalização, licenciamento e aprovação de projetos, assim como nos escritórios de planejamento e projeto dos setores público e privado além de toda a sociedade civil, participante da construção e gestão da cidade".

Vejamos, no entanto, de que modo a Carta foi realizada a fim de atingir tais objetivos. São adotados, conforme as descrições dos procedimentos metodológicos utilizados (Fernandes et al., 1993; PMSP, 1994), dois critérios básicos: 1) intervalos de declividade (menores que $25 \%$; entre 25 e $60 \%$; maiores que $60 \%$ ); 2) a individualização de "maciços" de solo e rocha (entendidos aqui especificamente como "litologias que resultam em perfis de alteração homogêneos"). A Carta Geotécnica resulta, assim, da sobreposição na mesma planta (o que se chama tecnicamente em Cartografia de "solução exaustiva") de uma carta clinográfica (o "mapa de declividades") e de um mapa litológico (ou, mais propriamente, das porções eluviais do regolito, a alteração de rocha in situ). $\mathrm{O}$ cruzamento dos dois resultaria, conforme os autores citados, na definição de "unidades territoriais homogêneas quanto a seu comportamento geotécnico", denominadas "unidades geotécnicas".

Ainda quanto aos procedimentos técnicos adotados, cabe ressaltar que é questionável o argumento da "dificuldade de obtenção de informações" causada pela "ocupação urbana densa", "ausência de afloramentos de solo ou rocha" e "acesso difícil em algumas áreas", visto que é justamente nas áreas de expansão urbana periférica, as áreas mais problemáticas do ponto de vista geotécnico, que mais se expõem os depósitos superficiais e regolitos em cortes, áreas erodidas, minerações etc, além das informações de investigações de subsolo disponíveis em várias entidades.

O objetivo final da Carta Geotécnica era, assim, fornecer subsídios a uma série de possíveis atividades, estudos e intervenções diversas a serem efetuadas no território do Município. E se justificava do seguinte modo: "A Carta [em 1:25.000, do IPT, apresentada em 1985] se mostrou insuficiente para atender a demanda por informações localizadas devido às limitações impostas pela escala e por apresentar muitas áreas de solo não caracterizado geologicamente. $O$ agravamento do quadro ambiental, a necessidade de obter informações sobre áreas não caracterizadas, aliados à demanda por dados em detalhe como: áreas adequadas para aterros e bota-foras, áreas com potencial para ocorrência de recalques, enchentes, escorregamentos, solapamento, erosão etc., concorreram para a proposição do presente trabalho." (PMSP, 1994).

DISCUSSÃO Como vimos, a Cartografia Geotécnica do Município de São Paulo vem apresentando problemas em termos de sua aplicação efetiva, o que é particularmente significativo em função do caráter desse tipo de trabalho. Estes problemas se dão, por um lado, em sua não incorporação aos 
chamados "instrumentos normativos" a que a Cartografia Geotécnica se propõem a subsidiar, o que poderia ser explicado eventualmente pelo desinteresse do poder público em sua utilização etc., ou seja, mecanismos de funcionamento do aparelho de estado que não discutiremos aqui. Mas, por outro lado, a não utilização significativa da Cartografia Geotécnica pode também, em nossa opinião, relacionar-se a problemas derivados dos próprios métodos de sua elaboração. Nesse sentido, interessa-nos discutir a fase mais avançada da Cartografia Geotécnica do Município de São Paulo, ou seja, o trabalho realizado na escala l: 10.000 .

Pelo que foi exposto na seção anterior notamos que a própria proposição do trabalho de detalhamento da Carta Geotécnica apresenta equívocos em suas concepções teóricas. As limitações de escala se mantêm em essência, visto que a Carta em $1: 25.000$ foi feita sobre bases 1: 10.000 reduzidas (e portanto contando com as mesmas generalizações cartográficas desta escala, apenas representadas em menor proporção). Mesmo levando em conta a escala 1: $10.000 \mathrm{em}$ si, a caracterização de fenômenos como escorregamentos, "solapamento", "recalques", inundações e outros nos parece que será obrigatoriamente genérica em excesso para ser aplicável (isto é, utilizada sem estudos adicionais).

Possivelmente áreas mais amplas de erosão e depósitos tecnogênicos de assoreamento e outros, como aterros de maior porte, possam ser bem caracterizados nesta escala. No entanto tais depósitos, aos quais associam-se grande parte dos problemas geotécnicos relacionados à urbanização, e pode-se dizer a parte mais grave, e que caracterizam uma situação geológica inteiramente nova, não são abordados com a devida importância, paradoxalmente, pela Carta em 1:10.000.

A aplicação à análise de riscos geológicos urbanos é referida especificamente nos trabalhos de Beuttenmüller \& Prado (1992) e Taveira et al. (1993). Estes últimos autores, ao analisarem o papel da Cartografia Geotécnica em 1: 10.000 no detalhado levantamento de riscos efetuado no loteamento do "Jardim Corisco", comentam que: "A carta geotécnica do Município de São Paulo foi, portanto, a base de informação sobre o meio físico de que se dispôs para o entendimento do comportamento do subsolo existente sob as moradias construídas neste loteamento. A conjugação de um elemento de geomorfologia, a declividade, com outro referente à constituição, que é o tipo de rocha e seu conseqüente solo de alteração residual, foi possível priorizar no processo de adaptação para legalização, certas porções do terreno, com preterimento de outras". Comentam ainda que: "o uso da Carta na escala de 1:10.000 permite ainda reconhecer em áreas próximas, com características geotécnicas semelhantes, a possibilidade de existência de 'novos Coriscos'"' (Taveira et ai, 1993).

No entanto, os próprios autores citados ressaltam que foi a classificação de risco elaborada o principal critério para subsidiar a legalização do loteamento (ou seja, sendo "passíveis de legalização" somente as áreas que não estivessem em "risco 1"). Ocorre que, para a definição dessas próprias áreas de risco utilizaram-se os indicadores: cortes; aterros; ocorrências de trincas de tração no terreno; inclinação de árvores; lançamentos de lixo, esgoto e águas servidas; existência de fossas. Portanto, somente critérios de caráter localizado e relacionados a fenômenos induzidos, demonstrando portanto o papel relativamente baixo que pode ter uma carta geotécnica em escala relativamente ampla na análise de fenômenos localizados, contrariamente ao que afirmam os autores citados.

Portanto, e talvez alcançando o cerne da questão, deve ser ressaltado que a mudança de escala da Cartografia Geotécnica do Município, de 1:25.000 para 1:10.000, não significou realmente um detalhamento qualitativo, uma vez que foram os mesmos objetos a serem representados (declividade, substrato geológico). A representação de processos e depósitos que, por outro lado, determinam decisivamente os problemas geológico-geotécnicos e o surgimento de áreas de risco no Município, tais como os depósitos tecnogênicos quinários (os aterramentos das várzeas, de espessuras iguais ou superiores ao Quaternário, as coberturas remobilizadas de encostas e cabeceiras de drenagem, os depósitos de "bota-fora" ou aterros tecnologicamente controlados), os grandes movimentos de terra, as coberturas superficiais, deixa via de regra de ser efetuada.

Devemos repetir, por ênfase, que este aspecto fica explicitado na Carta Geotécnica do Município de São Paulo em 1:25.000. Conquanto Ávila et al. (1987) reconheçam que "os fundos de vale nas áreas urbanizadas encontram-se invariavelmente entulhados ou assoreados por materiais de diversas naturezas", nenhuma conseqüência é tirada dessa constatação, visto que aos terrenos de várzea são associados, na elaboração da Carta, somente os depósitos aluvionares quaternários.

Além do que, mesmo em situações não modificadas pela ação humana, somente a identificação do tipo de maciço (eluvial) e da declividade predominante não determinam, necessariamente, as características do solo superficial (freqüentemente coluvionar), as quais podem estar associadas a condições geomorfológicas particulares. $\mathrm{O}$ caso mais expressivo pode ser o do espesso horizonte de "argilas porosas vermelhas", resultante da pedogênese profunda sobre sedimentos terciários no Espigão Central da bacia sedimentar, associadas ao ciclo que criou as principais planícies fluviais.

Sendo assim, um bom mapa geológico detalhado, sobre a base topográfica 1:10.000, e convenientemente interpretado (uma vez que a correta manipulação e aplicação de informações técnico-científícas exige cuidados especializados, aspecto no qual discordamos dos autores da $\mathrm{Carta}^{5}$ ) não poderia ter uma aplicação mais eficaz que a Cartografia Geotécnica na forma em que foi realizada no Município de São Paulo? A simplificação e generalização da realidade da natureza geológica para tornar possível seu entendimento pelos "planejadores" não comprometeria seu conteúdo ? Não seria mais adequado termos à disposição dos órgãos estatais de planejamento um serviço permanente de consultoria geológica e geotécnica que os assessorasse em um trabalho conjunto ${ }^{6}$ ? Tratam-se de questões pendentes e que merecem atenção dos geólogos.

$\mathrm{Na}$ verdade, em nossa opinião a concepção da Carta Geotécnica e de seu "detalhamento" em 1:10.000 representa um excesso de confiança no conteúdo científico da própria Carta. Esta, realizada em escala ampla, se pode ser utilizada para o cadastramento de situações e problemas geológicos urbanos específicos, não pode por si só ser utilizada para definir normas restritivas para áreas particularizadas, nem tampouco para dispensar estudos mais detalhados quando da proposição de algum empreendimento. Isto porque dentro de um mesmo compartimento (uma "área homogênea" à escala considerada e para um ou um conjunto de fatores considerados), as respostas às intervenções serão diferenciadas: 1) em função de peculiaridades geológico-geomorfológicas-geotécnicas não detectadas na escala da Carta; há abundantes exemplos disso, principalmente em relação à estabilidade de taludes; 2) em função do tipo de intervenção (isto é, da técnica utilizada e dos recursos disponíveis).

5 É nossa opinião que não se deve perder o conteúdo técnico-cientffico de um trabalho em função da tentativa de sua divulgação. A popularização do assunto é um processo necessário, mas independente da aplicação científica.

6 Este tipo de serviço seria particularmente interessante, inclusive, em função de que as Cartas Geotécnicas, particularmente aquelas em escalas grandes e em áreas urbanas, tendem a desatualizar-se com rapidez. 


\section{REFERÊNCIAS}

AB' SABER, A.N. 1977. Problemática da Desertificação e da Savanização no Brasil Intertropical. São Paulo, Instituto de Geografia, Universidade de São Paulo, Geomorfologia (53), 19p.

ÁVILA, I.G.; SUEMITSU, A.; MORETTI, A.O.; CHUNG, W.C.; PRANDINI, F.L.; SANTOS, M.T.N. 1987. Carta Geotécnica do Município de São Paulo. In: CONGRESSO BRASILEIRO DE GEOLOGIA DE ENGENHARIA, 5, São Paulo, Anais... ABGE, v.2, p.389-398.

BARROS, L.H.S. \& PELOGGIA, A.U.G. 1993. Cartografia Geotécnica como fundamento para a recuperação de áreas urbanas degradadas: o exemplo da favela do Jardim Eliane, Município de São Paulo. In: CONGRESSO BRASILEIRO DE GEOLOGIA DE ENGENHARIA, 7, Poços de Caldas, Anais... ABGE, v.2, p.83-92.

BEUTTENMÜLlER, G. \& PRADO, O. 1992. Riscos Geológicos e a Cartografia Geotécnica do Município de São Paulo. In: CONGRESSO BRASILEIRO DE GEOLOGIA, 37, São Paulo, Boletim de Resumos Expandidos... SBG, v.1, p.121-122.

CERRI, L.E.S. \& CARVALHO, CS. 1990. Hierarquização de situações de risco em favelas do Município de São Paulo, Brasil - critérios e metodologia. In: SIMPÓSIO LATINO-AMERICANO SOBRE RISCO GEOLÓGICO URBANO, 1, São Paulo, Atas... ABGE, p. 150-157.

COUTINHO, J.M.V. 1980. Carta Geológica da Região Metropolitana da Grande São Paulo (1: 100.000). EMPLASA, 2 folhas, São Paulo.

FERNANDES, A.; KAWAI, C.; GURDOS, C.; CARREGA, D.L.; SILVA, F.N.; VILLROTER, F.; BEUTTENMÜlLER, G.; TAKIYA, H.; MENEGASSE, L.; BARROS, L.; OLIVEIRA, M.A.; MOTTA, M.; DINIZ, M.; LANDGRAF JR., O.; PRADO, O.; SEPE, P.; NISHIMOTO, V.; NEWERLA, V. 1993. Detalhamento da Carta Geotécnica do Município de São Paulo. In: PREFEITURA DO MUNICÍPIO DE SÃO PAULO, SECRETARIA DO VERDE E MEIO AMBIENTE, A Questão Ambiental Urbana: Cidade de São Paulo, São Paulo, p. 381-388.

GESP - GOVERNO DO ESTADO DE SÃO PAULO 1990. Carta da Aptidão Física ao Assentamento Urbano (Guia de Utilização 1:50.000). São Paulo, SHDU-SCTDE-EMPLASA-IPT, 51p.

GONÇALVES, J.A. \& BROLLO, M.J. 1993. Mapeamento Geotécnico em Favelas do Município de São Paulo: setorização do risco e consolidação do terreno. In: CONGRESSO BRASILEIRO DE GEOLOGIA DE ENGENHARIA, 7, Poços de Caldas, Anais... ABGE, v.2, p.93-100.

PELOGGIA, A.U.G. 1992. Cartografia Geotécnica aplicada a projetos de urbanização de favelas no Município de São Paulo. In: CONGRESSO BRASILEIRO DE GEOLOGIA, 37, São Paulo, Boletim de Resumos Expandidos... SBG, v.1, p.54-55.

PELOGGIA, A.U.G.; SILVA, F.A.N; TAKIYA, H. BARROS, L.H.S ; FUJIMOTO. N.A.; FIGUEIREDO, R.B. 1992. Riscos geológicos e geotécnicos em áreas de precária ocupação urbana no Município de São Paulo. In: CONGRESSO BRASILEIRO DE GEOLOGIA, 37, São Paulo, Roteiros das Excursões... SBG, v. 11,24p.

PMSP - PREFEITURA DO MUNICÍPIO DE SÃO PAULO / SECRETARIA MUNICIPAL DO PLANEJAMENTO. 1985. Qualidade Ambiental. São Paulo, P.M.S.P., 31p (Série Documentos).
PMSP - PREFEITURA DO MUNICÍPIO DE SÃO PAULO / SECRETARIA MUNICIPAL DO PLANEJAMENTO 1992a. Política ambiental e gestão da cidade. In: Cadernos de Planejamento, Diário Oficial do Município de São Paulo (Suplemento), São Paulo, ano 37, n.243,24p.

PMSP - PREFEITURA DO MUNICÍPIO DE SÃO PAULO / SECRETARIA DA HABITAÇÃO E DESENVOLVIMENTO URBANO 1992b. Relatório de Gestão (Programa de ação nas áreas de risco em favelas, atendimento à emergência e verba de atendimento habitacional), São Paulo, vol. XIII, 24p, relatório interno (inédito).

PMSP - PREFEITURA DO MUNICÍPIO DE SÃO PAULO / SECRETARIA MUNICIPAL DO PLANEJAMENTO 1994. Relatório final do G.T. de detalhamento da Carta Geotécnica do Município de São Paulo, São Paulo, 24p, relatório interno (inédito).

PONCANO, W.L.; BISTRICHI, C.A.; CARNEIRO, C.D.R.; ALMEIDA, M.A.; PIRES NETO, A.G.; ALMEIDA, F.F.M. 1979. O conceito de sistemas de relevo aplicado ao mapeamento geomorfológico do Estado de São Paulo. In: SIMPÓSIO REGIONAL DE GEOLOGIA, 2, Rio Claro, Atas... SBG, Rio Claro, v.2, p.253-262.

PONCANO, W.L.; CARNEIRO, C.D.R.; BISTRICHI, C.A.; ALMEIDA, F.F.M.; PRANDINI, F.L. 1981. Mapa Geomorfológico do Estado de São Paulo. São Paulo, Instituto de Pesquisas Tecnológicas do Estado de São Paulo, v.1, 94p (Publicação IPT n 1183, Monografias 5).

PRANDINI, F.L.; ÁVILA, I.G.; COSTANZO JR., J.C.; CARLSTRON P, C.; BOTTURA, J.A.; TEIXEIRA. A.L. 1978. Uma Carta Geotécnica dos terrenos adjacentes ao canal do Rio Tietê, de Osasco a Guarulhos. In: CONGRESSO BRASILEIRO DE GEOLOGIA DE ENGENHARIA, 2, São Paulo, Anais... ABGE, v.1, p.281-296.

PRANDINI, F.L.; NAKAZAWA, V.A.; CAMPANÁRIO, M.A. 1992. Cartografia Geotécnica da Grande São Paulo. In: PROBLEMAS GEOLÓGICOS E GEOTÉCNICOS NA REGIÃO METROPOLITANA DE SÃO PAULO, São Paulo, Atas... ABAS/ABGE/SBG-SP, p.241-250.

PRANDINI, F.L.; NAKAZAWA, V.A.; FREITAS, C.G.L.; DINIZ, L.C. 1995. Cartografia Geotécnica nos planos diretores regionais e municipais. In: CURSO DE GEOLOGIA APLICADA AO MEIO AMBIENTE, ABGE/IPT, São Paulo, ABGE, p.187-202.

PUPO, G. \& LOPES, J.B. 1993. Urbanização de favelas: interação Geologia de Engenharia e Urbanismo. In: CONGRESSO BRASILEIRO DE GEOLOGIA DE ENGENHARIA, 7, Poços de Caldas, Anais... ABGE, v.2, p. 191-200.

TAVEIRA, L.; BARROS, L.H.S.; SEPE, P.M.; BACIC, R.F. 1993. Jardim Corisco: exemplo de aplicação da Cartografia Geotécnica no Município de São Paulo. In: PREFEITURA DO MUNICÍPIO DE SÃO PAULO - SECRETARIA DO VERDE E DO MEIO AMBIENTE, $A$ Questão Ambiental Urbana: Cidade de São Paulo, São Paulo, p.341-348.

Manuscrito NB012

Recebido em 03 de marco de 1997

Revisão do autor em 14 de abril de 1997 Revisão aceita em 17 de abril de 1997 